\title{
Designing the Re-layout of the Production Floor Using Integrated Systematic Layout Planning (SLP) and Simulation Methods
}

\author{
Masriah Mansur ${ }^{1}$, Ahmad Afif Ahmarofi2,; and Anferes Gui ${ }^{3}$ \\ ${ }^{1}$ Faculty of Industtrial Management, Universiti Malaysia Pahang, 26300 Pahang, Malaysia. \\ 2Department of Computer Science, Faculty of Computer and Mathematical Sciences, Universiti Teknologi MARA, 08400 Merbok, Kedah, Malaysia. \\ ${ }^{3}$ School of Information systems, Bina Nusantara University, Indonesia.
}

ABSTRACT - In the manufacturing company, an efficient production floor affects the productivity of the company. Thus, a well design production floor layout assists the company to achieve its objectives. In this regard, this study aims to design a new alternative production floor layout for the $\mathrm{XYZ}$ manufacturing company. The company facing the facility layout problem (FLP) where their workstation on the production floor was not located based on the activity-relationship. Thus, the company struggles to reduce the distance travel of their workers from one station to another by relayout their production floor. The Systematic Layout Planning (SLP) method was used to determine the best new alternative layout for the company. Subsequently, the AnyLogic simulation software was utilized to test the effectiveness of the layout by using the number of steps as the parameter. As a result, it is found that the total number of steps of workers in the production floor can be reduced from 16,554 steps (in existing layout) to 15,956 steps (in new alternative layout).
ARTICLE HISTORY

Received: $18-12-2020$

Revised: 31-1-2021

Accepted: $3-3-2021$

KEYWORDS

Facility layout problem (FLP); Systematic layout planning

(SLP);

Simulation;

Production floor;

Manufacturing

\section{INTRODUCTION}

Layout and design of space impact greatly how the work is done including the flow of work, materials and information through the system (Jain \& Yadav, 2017). In manufacturing industries, layout design is the main goal for maximization of productivity in manufacturing process. By properly designing the arrangement of facilities, excessive movement of the materials can be reduced in the floor production. Desai and Madhale (2019) stated that facilities layout is a significant thing that will affect efficiency of production process in manufacturing industry. Thus, a well-planned facilities layout could reduce the losses due to the ineffective material flow and material handling.

Furthermore, a good layout arrangement makes the flow of material in the production floor to be smooth and rapid that reduces the transport handling cost and idle time of man and machine, given the situation where the existing plant layout of one manufacturing company was not well-organized. By determining the total distance travelled of the worker from one workstation to another, the ineffectiveness of the existing layout can be determined (Low \& Wong, 2017). Relayout process can be done if there is congestion and bad utilization of space in floor production, excess stock in process at the facility, high materials handling distance, bottleneck at the workstation, idle time of facilities and workers, labour anxiety and discomfort, accidents and difficulty in controlling operations and personnel (Naik, 2016).

This study considers one of plastic manufacturing company in Malaysia where focusing on its production floor layout. The company having some problem which regards to their plant layout. Figure 1 shows the working flow in the existing layout of the XYZ company's production floor. 


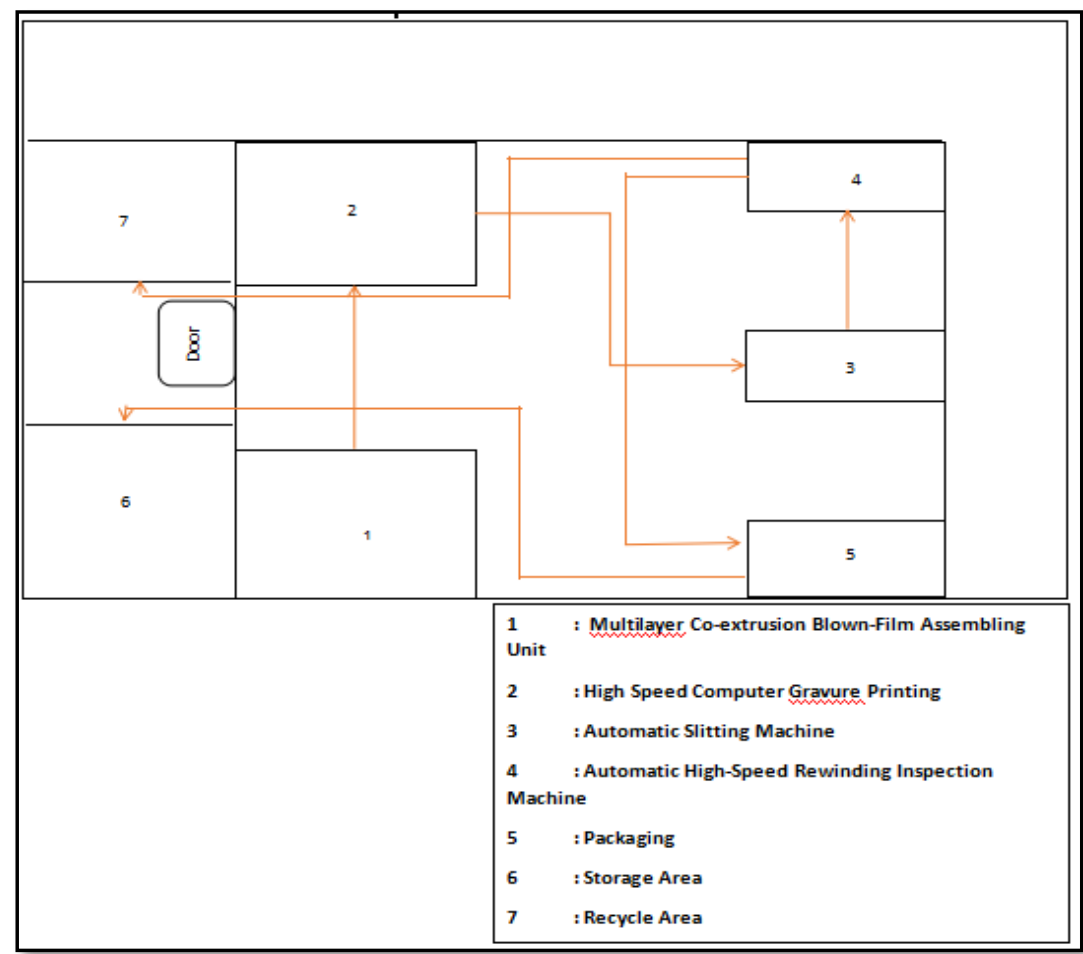

Figure 1 The working flow in the production floor of company XYZ

It shows that the placement of facilities in their production floor was not arranged with the activity-relationship. Thus, it will burden workers to move the work-in-process goods from one station to another station which affect the worker productivity. Consequently, workers need to travel a longer distance from one workstation to another. In this regard, this paper aims to design the production floor layout using systematic layout planning (SLP) and simulation methods. Thus, the systematic layout planning (SLP) method and simulation were integrated to solve this problem.

The remainder of this paper is organized as follows: Section 2 elaborates research methodology. Section 3 explains the results and discussions. Section 4 concludes the paper.

\section{RESEARCH METHODOLOGY}

This study was carried out by using both qualitative and quantitative method. Figure 2 presents the research design to relay out XYZ's production floor.

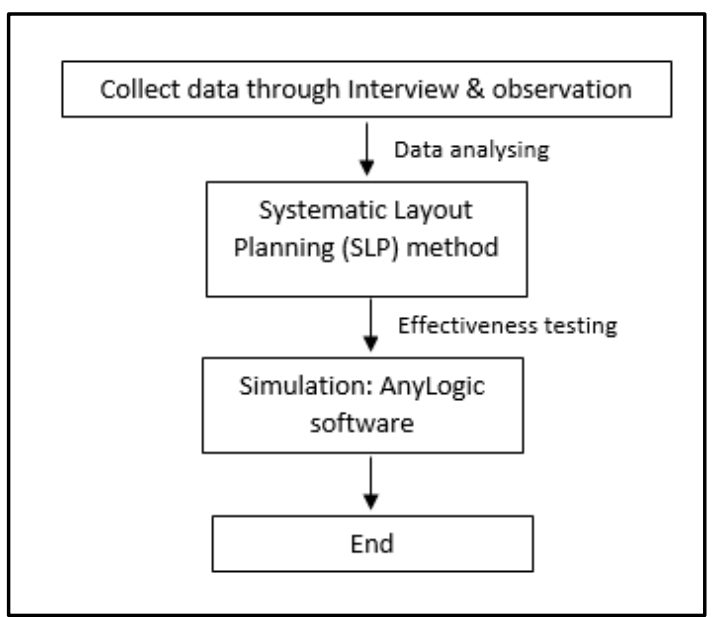

Figure 2 The research design

The first method is interview session. By using this method, the data and information were able to be collected for this study. The interviewee has interviewed the manager of the company and some workers in the company. The second method is observation where have been carried out through site visit to the company, the observation focusing in the current plant layout of the company and the movement of workers from one station to other. Then, after related data and 
information had been collected, the production floor was analysed through the SLP method and simulation tool, i.e., AnyLogic software.

According to Febriandini and Yuniaristanto (2019) SLP method is a procedure used to set the layout of facilities in the workplace based on the proximity and frequency relationship between one workstation and another workstation. Therefore, SLP is implemented by using three macro-phase which known as analysis, research and selection. The main step in phase 1 is the analysis of proximity requirements between each workstation to be positioned in the layout which was carried out by using the activity-relationship diagram. Result from this analysis were the input in phase 2 . In this phase, the layout alternatives were created by considering the practical constraints. Alternatives created were evaluated and phase 3 searched the best layout.

Subsequently, AnyLogic simulation software was used to test the effectiveness of the new alternative layout. The model is being formulate by building the flowcharts that shows all the process in the production floor of the company. After finished with the flowcharts, the simulation was run and the movement of workers from one station to another will be observed. The parameter for the simulation is the number of steps from one workstation to another. The effectiveness of the new layout is determined through the comparison with the existing layout.

\section{RESULTS AND DISCUSSIONS}

Before defined the final alternative, the existing layout will be analysed in term of the location of the facilities, the activity-related between each workstation and the distance travel by worker from each workstation to another. Figure 3 shows the current production floor layout of the XYZ company.

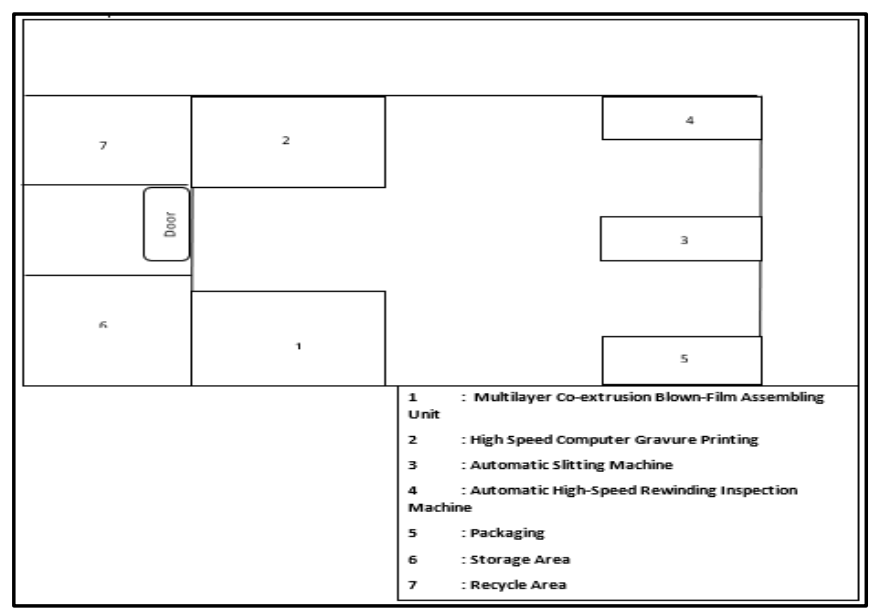

Figure 3 The current production floor layout of XYZ company

Basically, there are total seven work area with different processes and function as demonstrated by Figure 4.

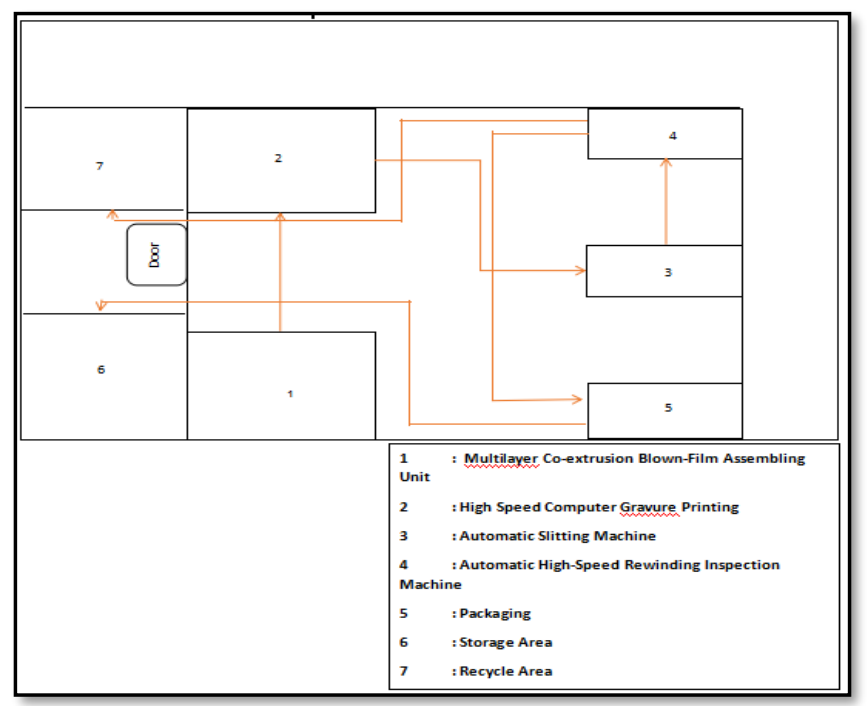

Figure 4 The activity flows in the existing production floor 
Furthermore, Figure 4 illustrates the movement of workers from one workstation to another workstation. At workstation 1, the raw materials are being processed by using the multilayer co-extrusion blown-film assembling unit. After being processed, plain plastics packaging is being transfer to the second workstation, high speed computer gravure printing is being used to print the logo and design on that plain plastics packaging.

After completed with the printing, the plastic packaging is being transfer to the next workstation for inspection. Here, the inspection is done both automatically and manual. Defect or rejected products are transfer to the recycle area. After going through the inspection, printed plastic packaging will go to the last workstation to be sort and packaged before stored in the storage area. After analysing the activity flows in the existing production floor. The activity-relationship diagram (ARD) is created in Figure 5 as follows.

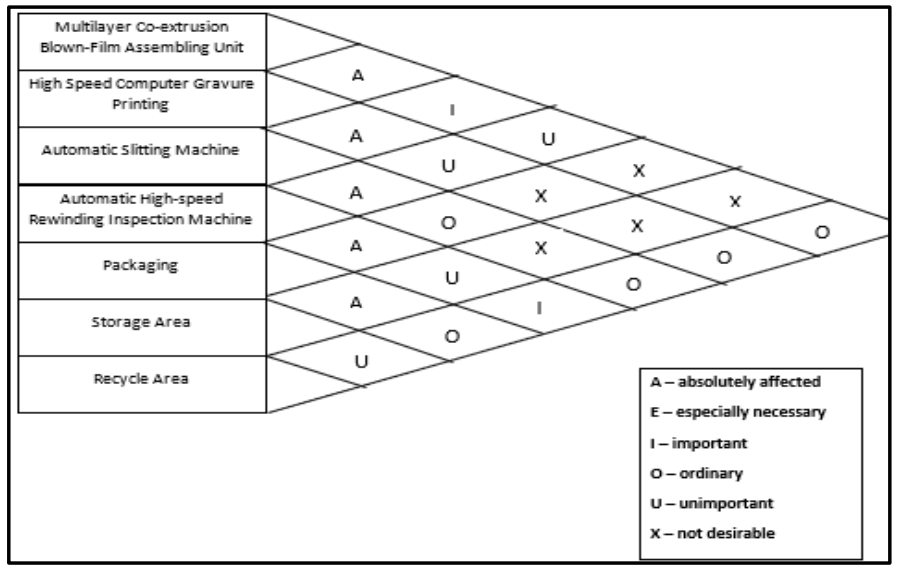

Figure 5 The Activity-Relationship Diagram of XYZ company

Figure 5 presents the relationship between each station in the production floor of XYZ company. This activity relationship diagram created by rate the closeness of each station according to the A, E, I, O, U and X. The main purpose of this activity relationship diagram was to indicate the relationship between station, and it will help in positioning the station for the improvement. Based on considered improvement, a new alternative will be created (Maina et al., 2018).

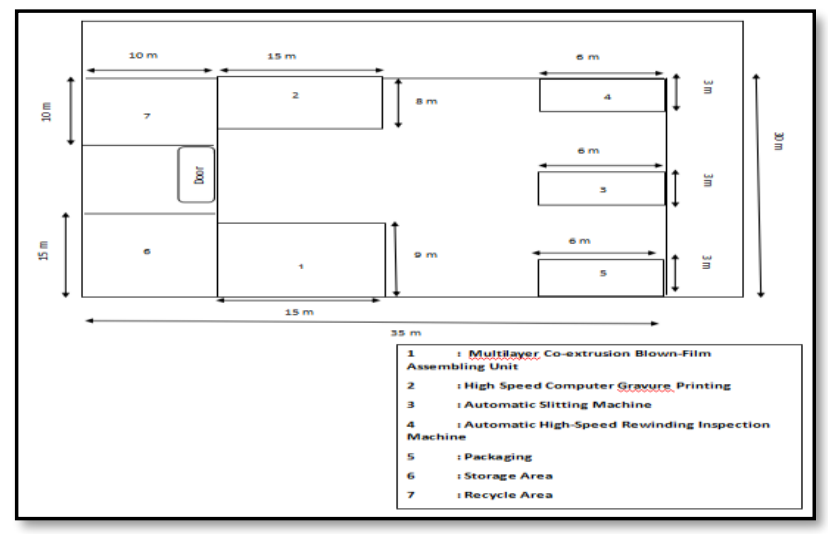

Figure 6 The dimension of the existing production floor layout of XYZ company

To create a new alternative layout, the available space and the space requirement for each workstation was being analysed. Figure 6 shows the dimension of the existing layout of XYZ company, with the total space area of $1050 \mathrm{~m}^{2}$. After analysed the facility location and the activity-relationship diagram of XYZ company. The new alternative layout is create considering the possible constraint (the available area). 


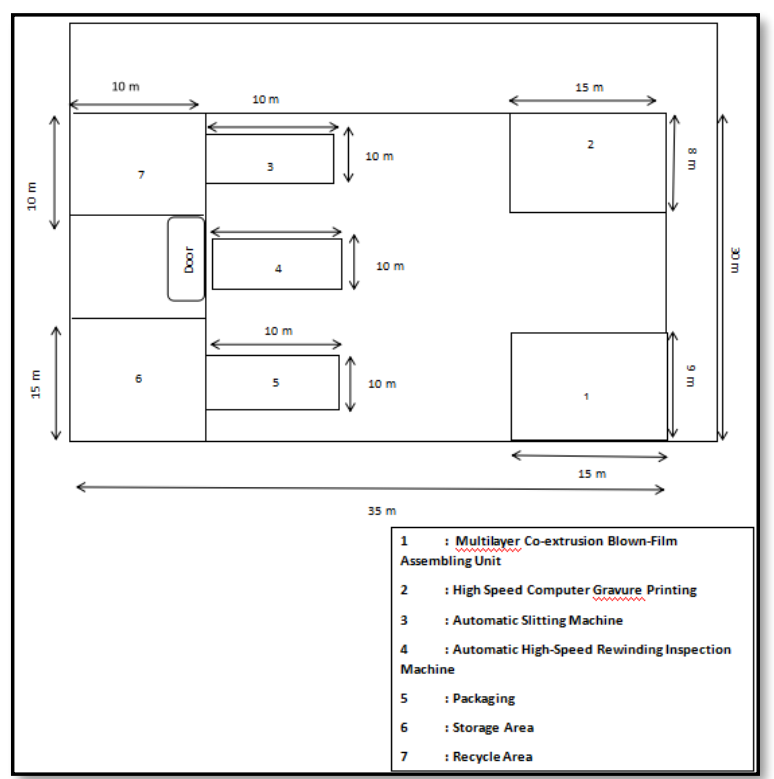

Figure 7 The new alternative production floor layout for XYZ company

Based on the new alternative layout as presented in Figure 7, position of workstation 3, 4 and 5 are located near to the storage area and recycle area. This is because all of these stations affected the storage area and recycle area. Meanwhile, workstation 1 and 2 does not really affected storage area are put at the other side. Subsequently, Figure 8 illustrates the activity flow in the new alternative layout.

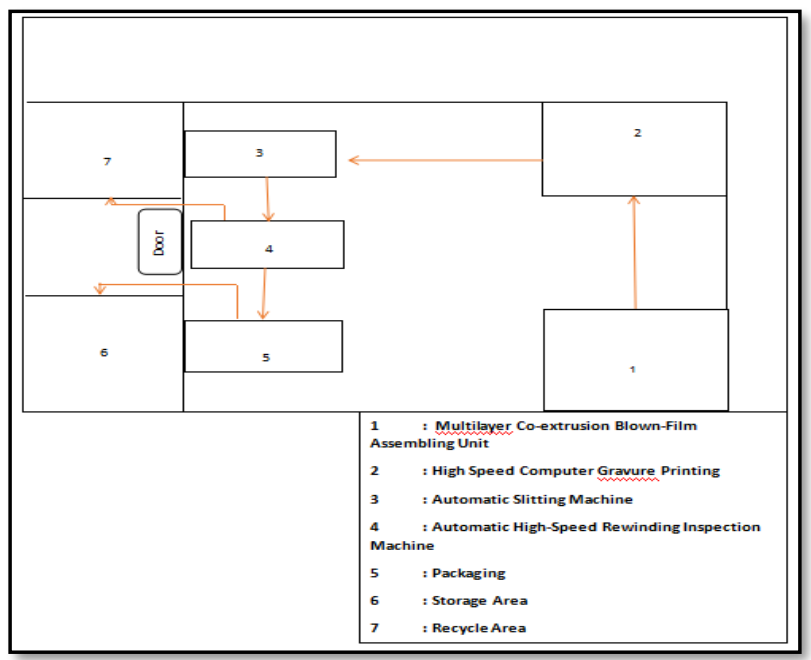

Figure 8 The activity flow in the new alternative layout.

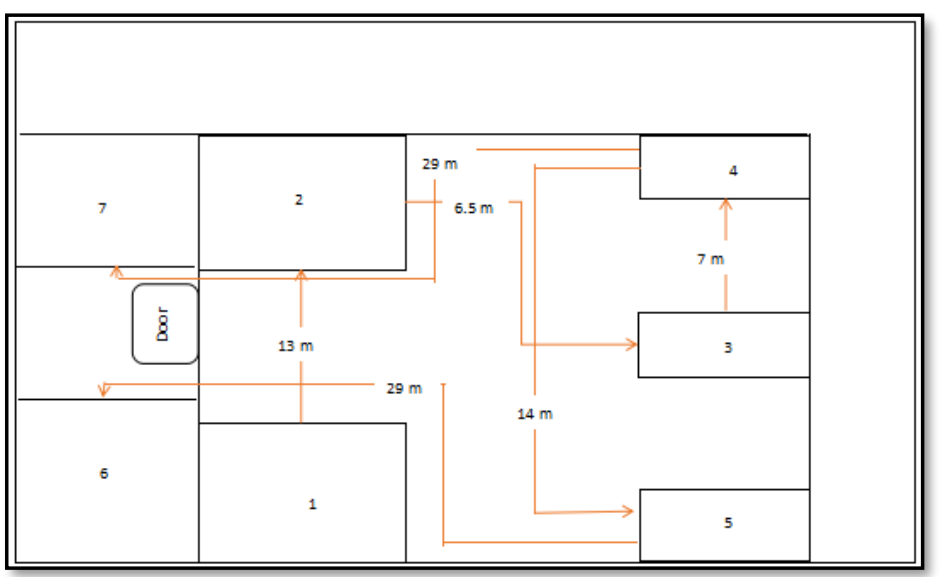

Figure 9 The total distance travel in the existing production floor layout of XYZ company. 
Figure 9 shows the distance travel by workers from each workstation to another workstation according to the activityrelationship process in the existing layout. The data was collected during the interview session with the XYZ company. The distance travel is summaries in the Table 1 as follows.

Table 1 The total distance from each workstation in the XYZ's production floor layout

\begin{tabular}{cc}
\hline Direction & Distance (meter) \\
\hline Station 1 to Station 2 & 13 \\
Station 2 to Station 3 & 6.5 \\
Station 3 to Station 4 & 7 \\
Station 4 to Station 5 & 14 \\
Station 4 to Station 7 & 29 \\
Station 5 to Station 6 & 29 \\
\multicolumn{2}{c}{ Total Distance Travel: 98.5 m } \\
\hline
\end{tabular}

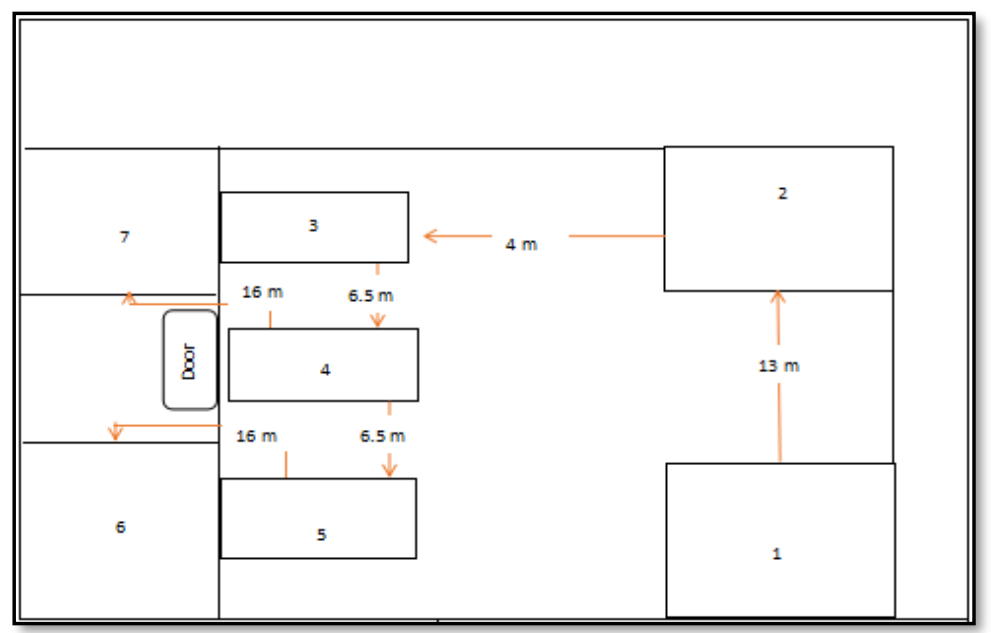

Figure 10 The distance travel in the new alternative layout.

Table 2 The total distance travel in the new alternative layout.

\begin{tabular}{cc}
\hline Direction & Distance (meter) \\
\hline Station 1 to Station 2 & 13 \\
Station 2 to Station 3 & 4 \\
Station 3 to Station 4 & 6.5 \\
Station 4 to Station 5 & 6.5 \\
Station 4 to Station 7 & 16 \\
Station 5 to Station 6 & 16 \\
\multicolumn{2}{c}{ Total Distance Travel: 62 m } \\
\hline
\end{tabular}

Based on the Figure 10 and Table 2, the total distance travel in the new alternative layout is around 62 meters, compare to the existing layout which is 98.5 meter. From this result, it shows that the total distance travel can be reduced about 36.5 meter. Short distance travel in the new alternative layout will give positive impacts on the productivity in the production floor.

After that, to study the effectiveness of the new alternative layout, AnyLogic simulation software is used to compare between the existing layout and the new alternative layout. The parameter that is used to compare the effectiveness is the total number of steps. 


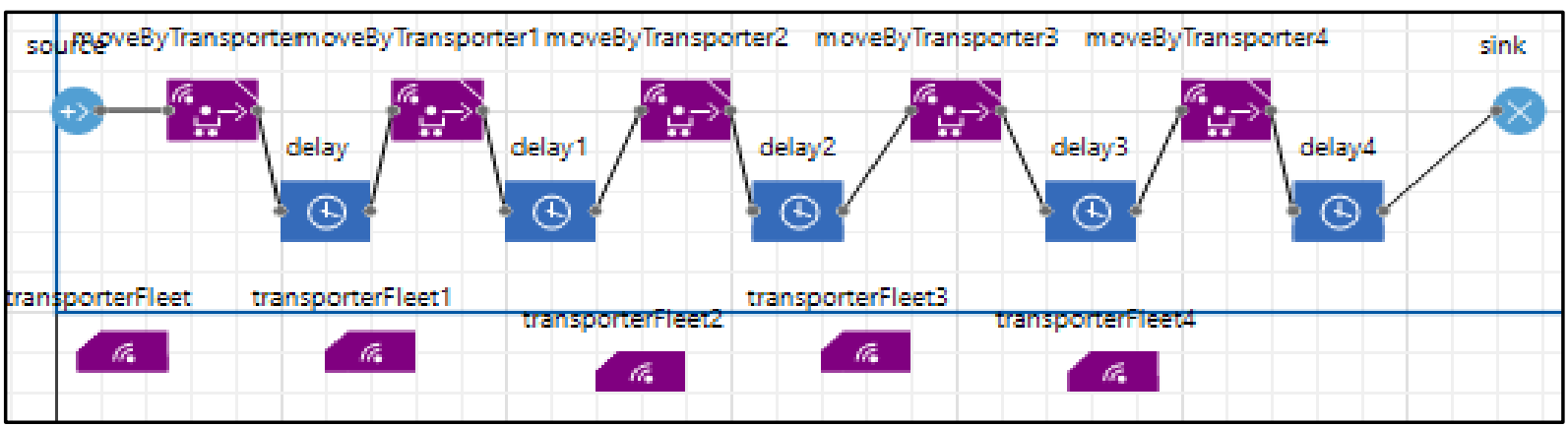

Figure 11 The flowcharts model of the production floor in the company XYZ

Figure 11 illustrates the flowcharts model of the production floor in the XYZ company through AnyLogic software. Delays represent the process in each workstation and transporter fleet represent workers in each workstation. Workers are set to minimum number in each workstation which is three people. Figure 12 demonstrates the existing production floor layout in 3D view.

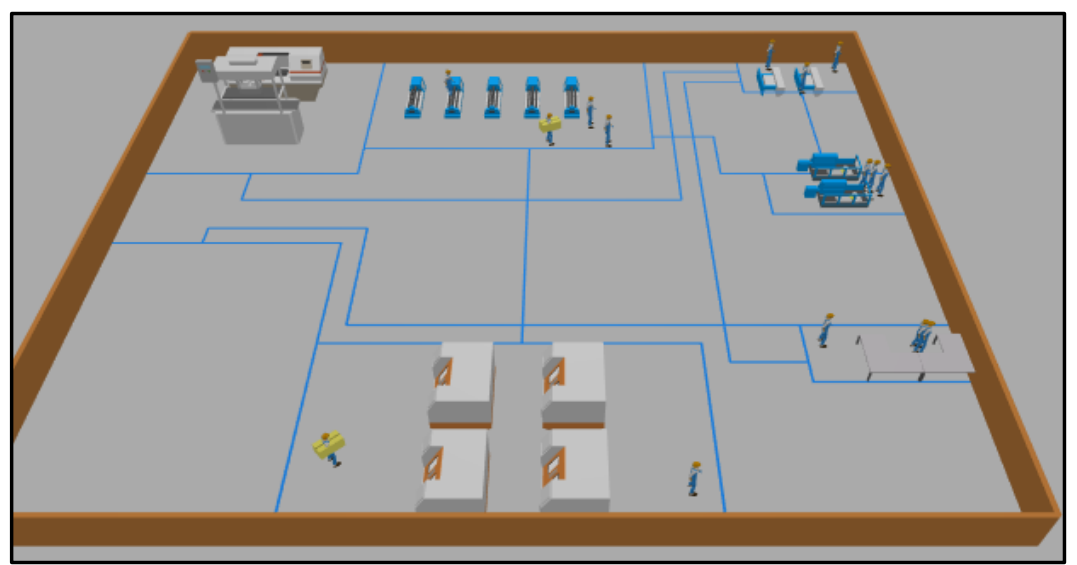

Figure 12 The existing production floor layout in 3D view.

The existing production floor layout is design following the measurement given by the company. The activity flow in the production floor is then being set accordance with the flowcharts as presented in Figure 11. After that, the simulation is run for about an hour and the result is shown in the Figure 13.

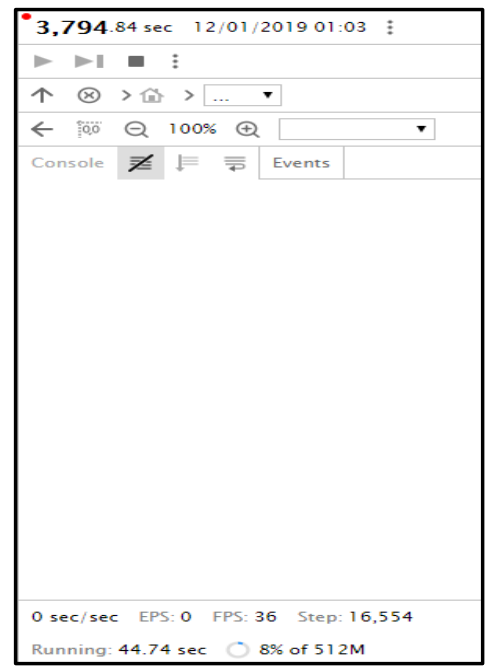

Figure 13 The simulation result for the existing layout.

Based on the simulation result in Figure 13, it shows that the total number steps in an hour is 16,554 steps. This result was compared with the new alternative layout. 


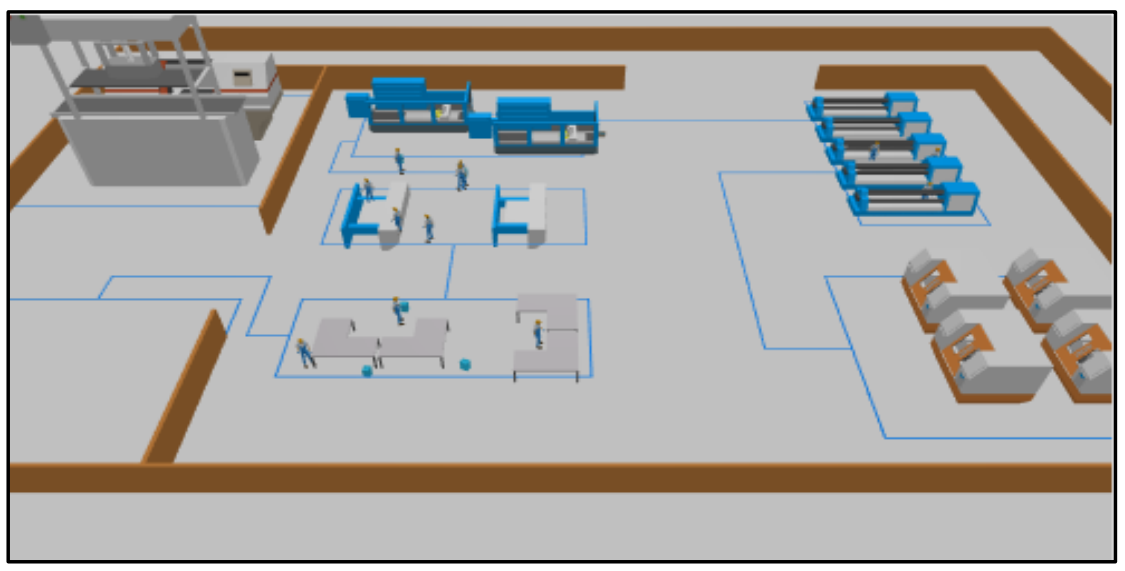

Figure 13 The new alternative layout of the production floor in 3D view.

The activity flow once again set up accordance with the flowcharts in Figure 11 into the new alternative layout in Figure 14 and the simulation was run for about an hour.

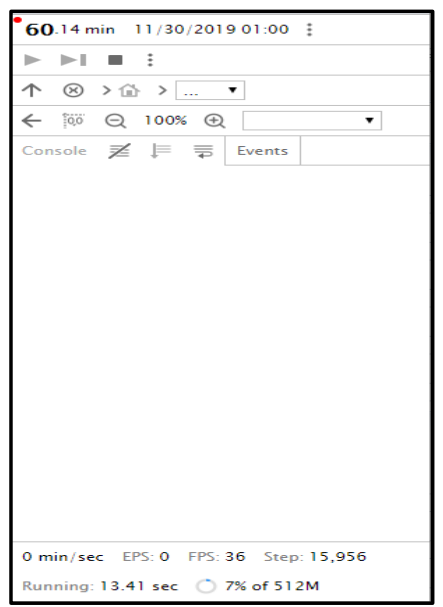

Figure 14 The simulation result for the new alternative layout.

From the result shown in Figure 14, it shows the total number of steps in an hour is 15,956 steps. This shows that the movement of workers are more efficient in the new layout compare to the existing layout. Thus, the proposed new alternative layout by using the SLP method is valid as it achieved the objectives of this study.

\section{CONCLUSION}

From the analysis by SLP methodology, it shows that the new alternative production layout can decreases the distance travel by workers for around 32.5 meter. When using the simulation for the effectiveness test, it shows the number of steps can be decreases for about 598 steps. However, this study has encountered some limitations where the measurement area for each station given by the company was not exactly precise. This is because, during the interview, the data given by the manager was only assumption as the company never consider the importance of their production floor layout, later it will affect the steps to come up with new alternatives layout. Thus, precise data needs to be used and it will only give a precise result.

\section{REFERENCES}

Desai, S. S., \& Madhale, P. A. K. (2019). Optimization of machining facility layout by using simulation : Case study, $1861-1865$.

Febriandini, I.F. (2019). Re-design facility layout using systematic layout planning method : a re-design facility layout using systematic layout planning method: a case study: Biopro Cosmeceutical Sdn. Bhd. In OP Conference Series: Materials Science and Engineering (Vol. 495, No. 1, p. 012027). IOP Publishing. https://doi.org/10.1088/1757-899X/495/1/012027.

Jain, M. S., \& Yadav, T. K. (2017). Systematic layout planning: A review of improvement in approach to pulse processing mills, International Research Journal of Engineering and Technology (IRJET), 4(5), 503-507.

Low, X. F., \& Wong, K. Y. (2017). Redesign and simulation of facility layout in a manufacturing company, Jurnal Mekanikal, 40(2), 53-60.

Maina, E. C., Muchiri, P. N., \& Keraita, J. N. (2018). Improvement of Facility Layout Using Systematic Layout Planning, 08(5), 3343.

Naik, S. B. (2016). A literature review on efficient, 7(2), 43-51. 


\section{CONFLICT OF INTEREST}

The author(s), as noted, certify that they have NO affiliations with or involvement in any organisation or agency with any financial interest (such as honoraria; educational grants; participation in speakers' bureaus; membership, jobs, consultancies, stock ownership, or other equity interest; and expert testimony or patent-licensing arrangements), or nonfinancial interest (such as personal or professional relationships, affiliations, expertise or beliefs) in the subject matter or materials addressed in this manuscript.

\section{AUTHORS' BIOGRAPHY}

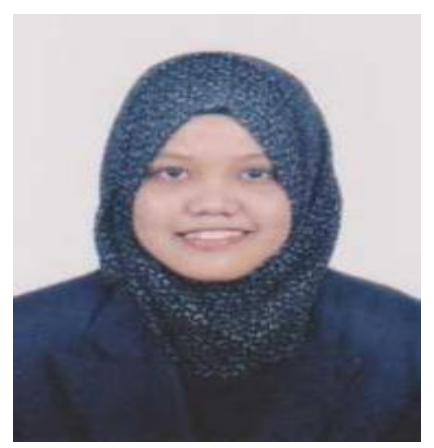

Author's Full Name: Masriah Mansur Author's Email: maszreahrh@gmail.com

Author Professional Bio: Masriah Mansur is a research student at Faculty of Industrial Management, Universiti Malaysia Pahang.

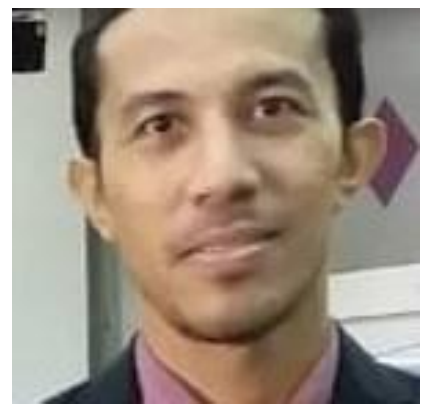

Author's Full Name: Ahmad Afif Bin Ahmarofi

Author's Email: afifphd@gmail.com

Author Professional Bio: Ahmad Afif is currently a senior lecturer at Department of Computer Science, Faculty of Computer and Mathematical Sciences, Universiti Teknologi Mara (UiTM) Kedah. His areas of expertise are Artificial Intelligence (Artificial Neural Networks), Computer Simulation (System Dynamics), and Optimization Method (Linear Programming/ Integer Programming).

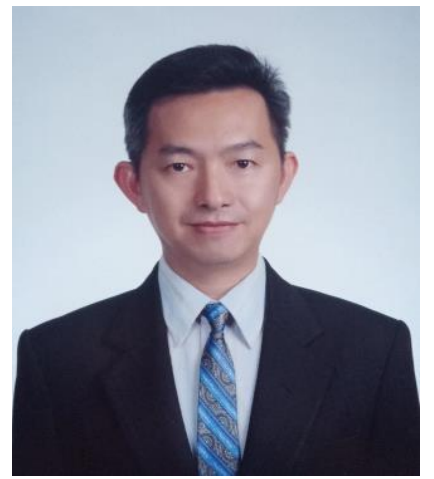

Author's Full Name: Anderes Gui

Author's Email: anderesgui@binus.edu

Author Professional Bio: Anderes Gui is serving as Associate Professor at School of lnformation systems, Bina Nusantara University, lndonesia. His research interest is in information system and technology management. 